\title{
Burden of herpes zoster and post-herpetic neuralgia in Sweden
}

Jonas Nilsson ${ }^{1 *}+$ Tobias Cassel $^{2+}$ and Lars Lindquist ${ }^{3}$

\begin{abstract}
Background: The societal economic burden of herpes zoster in Sweden is not well described today. This study is a top-down analysis of Swedish registers with the objective to describe the burden of herpes zoster and postherpetic neuralgia in Sweden during 2011.

Methods: Data for inpatient care; outpatient primary and specialized cares; the prescriptions of drugs, sick leave and the number or diagnostic tests were collected from Swedish national databases. The incidence of the disease was estimated based on the number of prescriptions of antiviral drugs.

Results: The incidence of herpes zoster was estimated to 315 and 577 cases per 100,000 people for patients at all ages and $>=50$ years, respectively. Almost 30,000 patients at all ages were diagnosed with herpes zoster and the societal cost to treat these patients, including the cost to treat those patients who later developed post-herpetic neuralgia, added up to nearly 227 MSEK (31.6 M€) which corresponds to 7,600 SEK (€870) per patient. The main contributors to the total cost for the treatment of $\mathrm{HZ}$ patients were primary care $(43 \%)$; sick leave (28\%); hospitalization (10\%) and specialist care (7 \%). Medication was a relatively small contributor with 8.5 MSEK (4 \%; $1.0 \mathrm{M} €$ ) to the overall costs for patients at all ages. The corresponding total cost including only patients 50 years and older was 168 MSEK (19.2 M€) or 8,200 SEK (€939) per patient.

Conclusions: The current study demonstrates that the burden of herpes zoster is significant in Sweden. The society, the health care payers and the patients potentially have a lot to gain by introducing a vaccination program to patients 50 years and older and as a consequence reduce the economic and clinical burden of herpes zoster and post-herpetic neuralgia.
\end{abstract}

\section{Background}

Herpes zoster (HZ), also known as shingles, results from reactivation of latent varicella-zoster virus (VZV) infection residing in the spinal and cranial sensory ganglia. The initial infection of VZV usually occurs during childhood and manifests clinically as chickenpox. $\mathrm{HZ}$ as a subsequent reactivation, more seldom as a result of reinfection, of VZV presents as a clinical syndrome characterized by a unilateral radicular pain and avesicular, distributed cutaneous rash [1]. The annual HZ rate in the general population has been estimated to be 3-6 cases per 1,000 person-years in the United States (US), the United Kingdom (UK) and Europe [2-6], and the

\footnotetext{
* Correspondence: Jonas.nilsson@optum.com

${ }^{\dagger}$ Equal contributors

'Mapi Group, Stockholm, Klarabergsviadukten 90D, SE-111 64, Stockholm, Sweden

Full list of author information is available at the end of the article
}

estimated average lifetime risk of $\mathrm{HZ}$ was approximately $30 \%$ reported from UK and Canadian studies [7]. The incidence and severity of $\mathrm{HZ}$ increase markedly with advancing age, about half of all cases occur amongst individuals 60 years old or older. In Sweden, a recent burden of illness study on HZ conducted by Studahl et al. [8] found similar results by analyzing data from Swedish national registries during 2006-2010. It reported that 2.7 per 1,000 persons were prescribed antiviral treatment for $\mathrm{HZ}$ every year and the prescription rate increased with age [8]. The overall hospitalization rate for $\mathrm{HZ}$ patients over 80 years was approximately three-fold higher than for $\mathrm{HZ}$ patients aged 70-79 years [8].

The most frequent complication of $\mathrm{HZ}$ is postherpetic neuralgia (PHN) usually defined as a neuropathic pain syndrome that persists or develops more than three months after the acute HZ infection and 
dermatomal rash have healed $[1,9]$. The frequency and severity of PHN also increase with advancing age. Among individuals who have had acute HZ, it is estimated that about $20 \%$ of those aged 60 years or older and more than $30 \%$ of those over 80 years develop PHN [9]. Approximately $90 \%$ of these complain that pain is a predominant symptom, often refractory to treatment, and about $2 \%$ may suffer from pain for many years [9, 10]. The burden of $\mathrm{HZ}$ and PHN placed on health care systems is therefore considerable.

The burden of HZ in Sweden from a clinical perspective has been discussed in a previous study by Studahl et al. [8] for the years 2006-2010. The objective of the current study is to assess the burden and societal costs for HZ and PHN in Sweden during 2011.

\section{Methods}

Data that has been analyzed in the current study were taken from Swedish national databases and were not based on patient level data; hence, an ethical approval was not needed and no additional permission was needed. Costs were presented as 2013 Swedish kronor (SEK), key costs ware also given in Euros within brackets. Costs were inflated to 2013 using the Consumer Price Index (CPI) taken from Statistics Sweden where necessary; Conversion rate SEK to Euros average during 2013: 8.6494], and the resource utilization was summarized for the year 2011. All costs and values obtained from the Swedish national databases were provided as unweighted means based on aggregated data across 2011. Information regarding the dispersion around the unweighted mean was not available and, therefore, the uncertainty will be tested in sensitivity analysis (see below).

\section{Target population}

The main analyses presented in the current study focus on the costs for patients at all ages diagnosed with $\mathrm{HZ}$ and PHN. The age dependent incidence of VZV infections manifested as chickenpox versus $\mathrm{HZ}$ has been described by Yih et al. [11], Jumaan et al. [12] and PérézFarinos et al. [13]. Based on these studies, and the fact that only patients 50 years and older are eligible for vaccination in Sweden, it was also of interest to present the cost and incidence specifically for these patients in addition to the costs and incidence for all patients.

\section{$\mathrm{HZ}$ and PHN Incidence}

The incidence of $\mathrm{HZ}$ was estimated from the number of prescriptions of antiviral drugs with specific package sizes as described in Table 1. Prescriptions were obtained from the Swedish National Pharmacy Register (SNPR) covering close to $100 \%$ of the prescribed medications. However, the number of antiviral prescriptions was
Table 1 Antiviral medications and specific packages ${ }^{\S}$ used for the treatment of $\mathrm{HZ}$

\begin{tabular}{llllc}
\hline Drugs & ATC $^{*}$ & DDD $^{* *}$ & \multicolumn{2}{c}{ Days } \\
& & $\begin{array}{l}\text { Package } \\
\text { size }\end{array}$ \\
\hline Aciclovir & J05AB01 & $800 \mathrm{mg} \times 5$ & 7 & 35 \\
Famciclovir & J05AB09 & $500 \mathrm{mg} \times 3$ & 7 & 21 \\
Valaciclovir & J05AB11 & $500 \mathrm{mg} \times 2 \times$ & 7 & 42 \\
& & 3 & &
\end{tabular}

${ }^{*}$ ATC $=$ Anatomic Therapeutic Chemical; **DDD = Defined Daily Dose; ${ }^{5}$ The same package sizes were also used by Studahl et al. ([8] and personal communication)

corrected slightly since not only HZ patients are prescribed antiviral medications (see section Drug treatment below). The incidence reported by Studahl et al. [8] was from 2006-2010 but was updated with data from 2011 in this study. The share of HZ patients who developed PHN was taken from Gauthier et al. [14]. Here the share of patients, who were diagnosed with $\mathrm{HZ}$ and developed PHN within three months in the UK, was used as the incidence of PHN also in Sweden. The incidence was reported as the number of patients who were diagnosed with HZ or PHN per 100,000 Swedish people during 2011.

\section{Mortality}

Deaths related to HZ (ICD-10: B02) were collected from the Swedish Causes of Death Register covering all the people who died and were registered as living in Sweden until 2011.

\section{Inpatient care}

The Swedish Association of Local Authorities and Regions [15] are conducting a country-wide project to support the calculation of patient-related costs of care. As a result, the cost per patient for the treatment of various diagnoses is publically available via the KPP (KPP stands for cost per patient) database [15]. Although the KPP database does not cover the entire country yet, the costs for the treatment of HZ (DRG = 421) and PHN (DRG = 020) were taken from this database.

The number of inpatient treatments of $\mathrm{HZ}$ as primary cause (ICD-10: B02) and PHN as primary cause (ICD-10: G53.0), as well as the average duration of hospitalization, were taken from the Swedish National Patient Registry (held by the Swedish Board of Health and Welfare).

\section{Outpatient specialist care}

Statistics covering specialist care performed by physicians who are not general practitioners (GPs), are available from the Swedish National Patient Registry. The number of outpatient visits to specialist care with $\mathrm{HZ}$ or PHN as a primary or secondary diagnosis during 2011 was included in the analyses. A visit to a specialist was 
assumed to cost as a visit to an average specialist (average of the cost from visiting an ophthalmologist, neurologist, dermatologist, pain specialist or an infection specialist). Unit costs for the visits to the different types of care were derived as the average cost from the different regions and county councils in Sweden [16-20] as presented in Table 2.

\section{Outpatient primary care}

Primary care data for HZ and PHN patients during 2011 were extracted from Västra Götaland county council (VGR) and scaled to the entire Swedish population based on the share of the population the VGR county council is covering, which currently is $16.8 \%$ (1.59 M people) of the Swedish population. The VGR register all care (primary and specialist) consumed by its population in a local database. Primary care predominantly involved visits to general practitioners, doctors on call or home care visits. All the unit costs are listed in Table 2. The cost for a physician on call was estimated to be $50 \%$ higher than a regular visit to a GP as suggested in the pricelist from South-East Sweden [16].

\section{Diagnostic tests}

Herpes Zoster is predominately diagnosed based on the clinical situation; however, a couple of diagnostic tests are being used for patients with HZ or suspected HZ. The number of diagnostic tests performed with $\mathrm{HZ}$ patients was available in the Stockholm county council (Faktureringsunderlag Medicinsk Service (FUMS)). The tests used for $\mathrm{HZ}$ patients included IgG, a serologic laboratory test used to identify previous exposure to VZV and immunity, and second, measuring the presence of DNA in blisters or used as a laboratory diagnostic test of VZV-infected patients. The total number of tests performed in Sweden during 2011 was derived based on the share of the total population covered by the Stockholm county council, which corresponds to $22.1 \%(2.09 \mathrm{M}$ people). The cost per diagnostic test (940 SEK (€109)) including IgG and DNA was taken from the list price at a commercial vendor [21].

\section{Drug treatments}

Prescriptions of drugs to patients at all ages and $>=50$ years, during 2011 were extracted from the SNPR. In general, $\mathrm{HZ}$ patients are prescribed antiviral drugs only in the package sizes listed in Table 1, with enough pills to cover seven days of treatment. Therefore, the corresponding number of patients was used as a measure of the incidence of HZ during 2011 [8]. Antiviral drugs can also be prescribed to patients with other infections than $\mathrm{VZV}$, e.g., primary infections with VZV, as outlined by Studahl et al. [8]. To correct for this, prescriptions with the words: simplex, genital, mouth, labial, varicella, prophylaxis or chickenpox in the patient information field were excluded, amounting to $12 \%$ of the antiviral prescriptions [8].

Among those patients who were prescribed antiviral drugs, other drugs related to the treatment of $\mathrm{HZ}$ and $\mathrm{PHN}$ were also collected, including non-selective monoamine re-uptake inhibitors (e.g., amitryptiline), antileptics (e.g., gabapentin and pregabalin), opiods (e.g., tramadol) and anti-depressants (e.g., venlafaxine). As the number of prescriptions of other drugs than antiviral drugs was based on the same patients who were prescribed antiviral drugs, the number of prescriptions of other drugs was adjusted downwards by $12 \%$ to correct for the patients with other infections than VZV (see above).

The cost per package was assumed to be equal to the cheapest competitor in case no price was available in Farmaceutiska Specialiteter i Sverige (FASS) [22].

\section{Sick leave}

Data regarding sick leave for patients who were off sick more than 14 days due to HZ/PHN during 2011 were obtained from the Swedish Social Insurance Agency (SSIA). Sick leaves shorter than or equal to 14 days are not registered by the SSIA since employers are

Table 2 Cost per outpatient visit to primary and specialist cares

\begin{tabular}{|c|c|c|c|c|}
\hline Care & $\begin{array}{l}\text { Average cost per } \\
\text { visit (SEK) (SD) }\end{array}$ & $\begin{array}{l}\text { HZ:Number of visits; } \\
\text { all ages ( }>=50 \text { years) }\end{array}$ & $\begin{array}{l}\text { PHN: Number of visits; } \\
\text { all ages ( }>=50 \text { years) }\end{array}$ & Source \\
\hline \multicolumn{5}{|l|}{ Outpatient care (primary) } \\
\hline General practitioner (GP) & $1544(214)$ & 47047 (35 479) & $882(799)$ & {$[17,18,20]$} \\
\hline Physician on call & $2316(321)$ & $10534(6$ 904) & $12(0)$ & $\begin{array}{l}50 \% \text { higher than } \\
\text { GP visit [16] }\end{array}$ \\
\hline Home care* & $422(\mathrm{NA})$ & $1848(1765)$ & $30(30)$ & {$[19]$} \\
\hline \multicolumn{5}{|l|}{ Outpatient care (specialist) } \\
\hline Specialist visitt* & 2399 (732) & 6517 (5 292) & $617(570)$ & $\begin{array}{l}\text { Average of cost to } \\
\text { specialists }^{* *}\end{array}$ \\
\hline
\end{tabular}

*Primary care organized home care; ${ }^{* *}$ Average costs (ophthalmologist, neurologist, dermatologist, pain specialist, infectious specialist) calculated from pricelist in Norrland county council, Västra Sjukvårdsregionen, Sahlgrenska hospital, Stockholm and Gotland county council, Linköping county council and Södra Sjukvårdsregionen 
responsible for the payment of sickness benefits during the first two weeks of sick leave. Therefore, the number of days of sick leave below this threshold was estimated based on data in a previous study. Drolet et al. [23] found that the majority of employed $\mathrm{HZ}$ patients (64\%) reported an average absence from work of $27 \mathrm{~h}$ during the first 30 days of sickness. White et al. [24] found that HZ patients (18-65 years) in the US were on sick leave on average $26.5 \mathrm{~h}$ the first year after diagnosis; no specification on how these hours were distributed during the index year was provided in the study. In a telephone survey performed in the US by Singhal et al. [25] it was found that patients between 50-64 years were on average away from work $31.6 \mathrm{~h}$ per $\mathrm{HZ}$ episode. In those cases where the duration of the HZ episode was less than a month, patients lost on average $12.1 \mathrm{~h}$ of work. In addition to the absenteeism (time away from work), presenteeism-related work loss (for those who go to work despite their illness) could not be estimated but could add to the sick-leave related work loss as shown by Drolet et al. [23] and Singhal et al. [25].

In the current study, the work loss reported by Drolet et al. [23] ( $27 \mathrm{~h}$ the first 30 days from index date) was used as an estimation of the work loss for Swedish HZ patients during the first 13 days of illness. Thus, patients were off sick on the average 3.38 days (assume eight hours of work per day; $27 / 8=3.38$ ) if the sickness period was less than 14 days.

The number of employed HZ patients was calculated based on the employment rate (per 10-year age groups from 15 to 74 years old), including both males and females, in Sweden during 2011 obtained from Statistics Sweden [26].

To calculate the cost for lost production for patients on sick leave the average monthly salary was obtained from Statistics Sweden [26]. The daily wage was derived assuming $40 \mathrm{~h}$ of work per week and an employer's contribution of $31.42 \%$ [27] yielding 1,742 SEK (€201) per day.

\section{Sensitivity analysis}

Parameters that were estimated rather than obtained from any registers, i.e., the number of sick leave days shorter than 14 days, the GP consultation cost, daily hospitalization cost and the cost of drugs, were included in one-way sensitivity analyses experiments. The base case values were increased with $25 \%$ for all parameters except for the number of short term sick leave days that was increased with $50 \%$. The impact on the total cost of $\mathrm{HZ}$, including patients at all ages, was estimated for each experiment.

\section{Results}

\section{Incidence}

The incidence of HZ during 2011 is presented per age group in Fig. 1. In total, 29,900 (all ages) and 2,860 patients ( $>=50$ years) were diagnosed with $\mathrm{HZ}$ and PHN in Sweden during 2011, respectively. The corresponding number for patients 50 years and older with a diagnosis of $\mathrm{HZ}$ was 20,446 . The incidence of $\mathrm{HZ}$ is clearly higher for the group of patients older than 50 years compared to the whole population with 577 and 315 cases per 100,000 persons, respectively (Fig. 1). The incidence of PHN was only estimated for patients older than 50 years to 81 cases per 100,000 persons.

\section{Mortality}

Only eleven people died from HZ in Sweden during 2011 (0.12 per 100,000 people) and it was assumed that death did not contribute with any significant cost to the overall burden of $\mathrm{HZ}$.

\section{Health care utilization}

In Table 3, the number of visits to the different types of care utilized for the treatment of $\mathrm{HZ}$ and $\mathrm{PHN}$ are

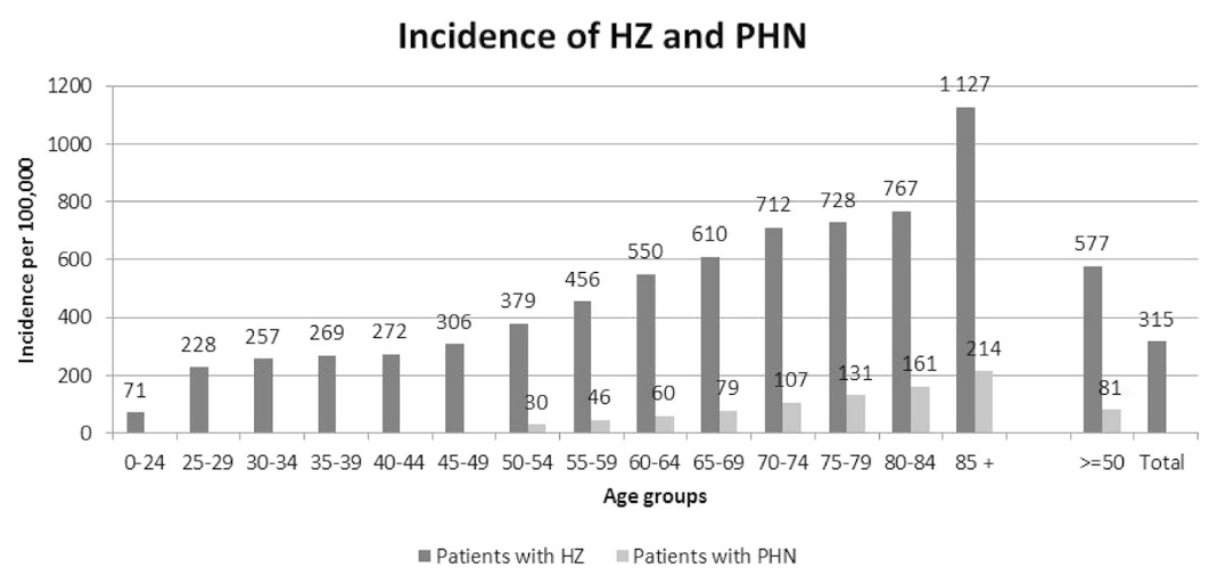

Fig. 1 The incidence of herpes zoster (HZ) and post-herpetic neuralgia (PHN) during 2011 (incidence per 100,000 persons) 
Table 3 Number of health care visits for $\mathrm{HZ}$ and PHN patients during 2011 including: inpatient care (hospitalization), outpatient care (primary) and outpatient care (specialist)

\begin{tabular}{llll}
\hline Type of care & Diagnosis & Number of visits; all ages (>=50 years) & Total cost; all ages (> =50 years) (SEK) \\
\hline Inpatient care (hospitalization) & HZ & $725(640)$ & $23342200(21784000)$ \\
& PHN & $222(217)$ & $11107400(11014000)$ \\
Outpatient care (primary) ${ }^{* *}$ & $\mathrm{HZ}$ & $59457(44147)$ & $97876300(71524300)$ \\
& $\mathrm{PHN}$ & $924(829)$ & $1402800(1246300)$ \\
Outpatient care (specialist) & $\mathrm{HZ}$ & $6517(5292)$ & $15634300(12695500)$ \\
& $\mathrm{PHN}$ & $617(570)$ & $1480200(1367400)$ \\
Total: & & $150843200(119631400)$ \\
\hline
\end{tabular}

*Swedish National Patient Registry; **Numbers from Västra Götaland County Council scaled to Sweden based on share of the population

summarized, including inpatient and outpatient (primary and specialist) care. Clearly, the dominating medical resource use for $\mathrm{HZ}$ was outpatient visits to a physician with almost 60,000 visits followed by outpatient visits to a specialist with 6,500 visits in 2011 . The number of visits is real world data and, therefore, each visit will incur a cost regardless if a patient contributed with more than one visit.

From the KPP database the costs per $\mathrm{HZ}$ and PHN hospitalizations were taken and equaled 41,000 SEK $(€ 4,800)$ and 32,000 SEK $(€ 3,700)$, corresponding to 7.87 and 5.44 days of hospitalization, respectively. The daily hospitalization costs were calculated for $\mathrm{HZ}$ and PHN to 5,261 SEK (€608) and 5,840 SEK (€675), respectively. The average hospitalization time for patients older than 50 years was calculated to 6.47 days and 8.69 days for $\mathrm{HZ}$ and $\mathrm{PHN}$, respectively, based on data from the Swedish National Patient Registry. Note, that the number of hospitalization days, used to estimate the total hospitalization costs, were taken from the Swedish National Patient Registry, rather than the KPP-database, as the former was based on all registered hospitalisations. Only a small part $2.7 \%$ and $5.5 \%$ of the $\mathrm{HZ}$ and $\mathrm{PHN}$ patients 50 years and older, respectively, were hospitalized while incurred $13 \%$ of the total costs.

The treatment of $\mathrm{HZ}$ patients incurs clearly more resource use than the treatment of PHN patients with estimated costs for hospitalization of 23 and 11 MSEK (2.7 and 1.3 M€), primary care of 98 and 1 MSEK (11 and $0.1 \mathrm{M} €$ ) and specialist care of 16 and 1 MSEK (1.8 and 0.1 M€), respectively (Fig. 2). The share of hospitalization costs for PHN patients was higher relative to the cost for $\mathrm{HZ}$ patients as compared to the corresponding costs for the outpatient cares.

The overall health care costs for $\mathrm{HZ}$ and $\mathrm{PHN}$ patients add up to over $151 \mathrm{MSEK}$ (17.6 M€) where the cost for primary care is dominating. For patients 50 years and older the corresponding cost is 120 MSEK (14 M€) which is $79 \%$ of all the health care costs.

\section{Diagnostic tests}

In Sweden, the total cost for diagnostic tests performed to establish the $\mathrm{HZ}$ diagnosis was estimated to around 4
MSEK (0.5 M€; IgG and DNA with 3 MSEK and 1 MSEK, respectively) during 2011 based on 3,686 and 812 numbers of tests for IgG and DNA, respectively. Including only patients $>=50$ years the total cost was almost 3 MSEK (0.3 M€).

\section{Drug treatments}

The total costs of drug treatment were derived from the number of prescriptions of antiviral drugs and non-viral drugs to HZ/PHN patients and the cost per prescription [22] (Table 4). In total, the antiviral drugs and non-viral drugs contributed with around 8.5 MSEK (0.99 M€) to the overall burden of $\mathrm{HZ}$ in 2011 in all ages. Out of the 6 MSEK $(0.7 \mathrm{M} €)$ that was spent on anti-viral drugs, $72 \%$, $24 \%$ and $5 \%$ were spent on valaciclovir, aciclovir and famciclovir, respectively. Non-viral drugs included amitryptiline (mono-amine reuptake inhibitors), gabapentin and pregabalin, tramadol (opioids) and venlafaxine (antidepressant). Patients 50 years and older accounted for $69 \%$ (5.9 MSEK; 0.7 M€) of the total drug cost.

\section{Sick leave}

During 2011, 370 patients with the diagnosis HZ were on sick leave for an average length of 51 days, based on information from the SSIA. In addition, approximately 8,500 patients were on sick leave less than 14 days with an average length of 3.4 days. The major societal economic consequence of sick leave is cost for lost productivity as presented in Table 5. Out of the 22,800 $\mathrm{HZ}$ patients in working age with reported sick leave (20-74 years) 13,800 were employed during 2011.

The total sick leave cost for all patients during 2011 was estimated to 63.2 MSEK (7.3 M€) (40.0 MSEK (4.6 $\mathrm{M} €$ ) for patients $>=50$ years).

\section{Total costs}

In Sweden, during 2011, the overall societal cost of $\mathrm{HZ}$ and PHN was estimated to $227 \mathrm{MSEK}$ (26.2 M€) including patients at all ages which corresponds to on average 7,600 SEK (€880) per $\mathrm{HZ}$ patient. If only patients 50 years and older were included the overall cost was 


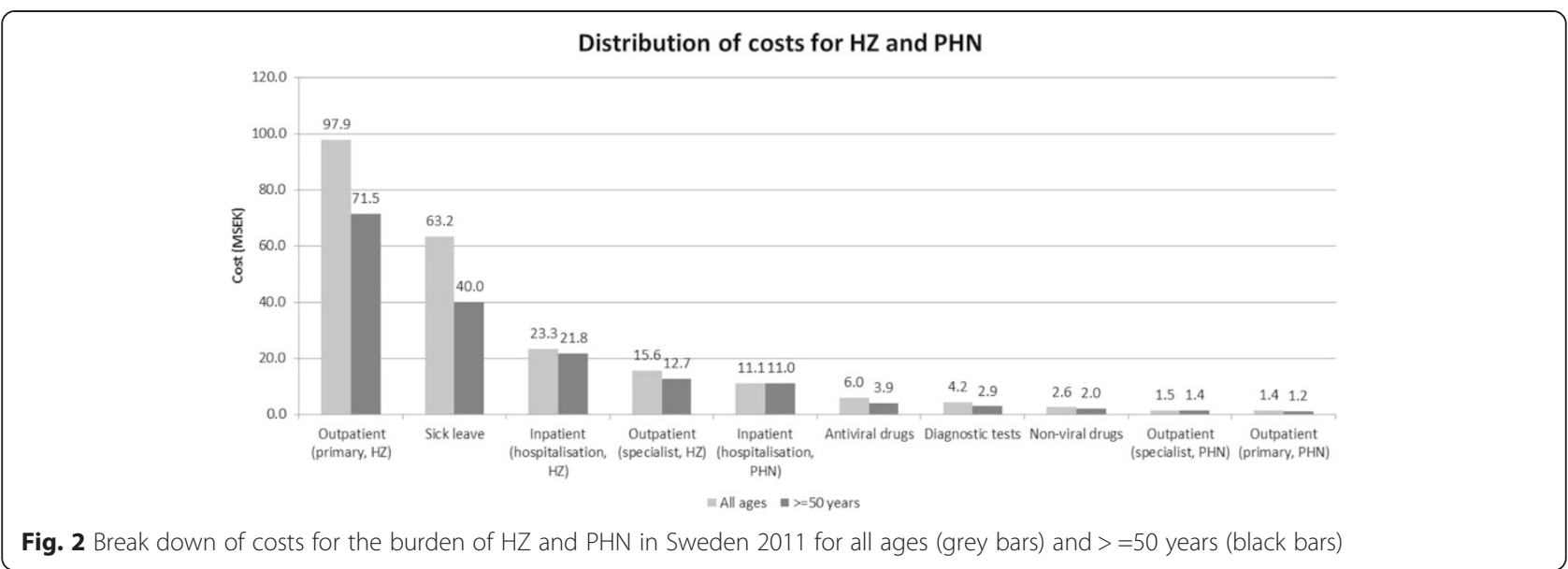

estimated to $74 \%$ of the costs (168 MSEK; $19.5 \mathrm{M} €$ ). The main contributors to the total cost for the treatment of $\mathrm{HZ}$ patients were primary care (43\%); sick leave (28 $\%)$; hospitalization (10\%) and specialist care (7 \%). Medication was a relatively small contributor with $4 \%$ (8.5 MSEK; $0.99 \mathrm{M} €$ ) to the overall costs for patients at all ages.

\section{Sensitivity analysis}

To test how sensitive the overall cost was to changes in the estimated number of short term sick leave days these were increased with $50 \%$ from 3.4 days to 5.1 days per employed $\mathrm{HZ}$ patient and year. The total cost increased from 227 MSEK (26.2 M€) in the base case to 242 MSEK (6 \% increase; $28.3 \mathrm{M} €$ ). Sensitivity analyses were also conducted for a few other estimated parameters: increasing the GP consultation cost with $25 \%$ increased the total cost with $8 \%$ to 245 MSEK (28.6 M€); increasing the daily hospitalization cost with $25 \%$ increased the total cost with $4 \%$ to 235 MSEK (27.2 M€) and similar for the drug cost increased the total cost slightly to 229 MSEK (26.5 M€).

\section{Discussion}

During 2011, almost 30,000 patients were diagnosed with HZ/PHN and the societal costs to treat these patients, including the costs to treat patients who later developed PHN, added up to nearly 227 MSEK (26.2 M€).

Table 4 Costs for drugs prescribed to $\mathrm{HZ}$ patients at all ages during 2011. In parenthesis prescriptions for patients $>=50$ years

\begin{tabular}{lll}
\hline Drug & $\begin{array}{l}\text { Number of prescriptions, } \\
\text { all ages }(>=50 \text { years) }\end{array}$ & $\begin{array}{l}\text { Total cost all ages } \\
(>=50 \text { years) (SEK) }\end{array}$ \\
\hline Antiviral & $32640(22195)$ & $5980800(3925200)$ \\
Non-viral & $22734(18$ 022) & $2577500(1962600)$ \\
Total: & & 8558300 (5 887 800)
\end{tabular}

*The number of prescriptions was adjusted downwards with $12 \%$ to correct for prescriptions to other diagnosis than $\mathrm{HZ}$
The corresponding cost when only patients 50 years and older were considered adds to 168 MSEK (19.5 M€). In the study by Studahl et al. [8] it was estimated that just above 28,000 patients received antiviral drugs during 2010. They also demonstrated evidence of an increasing number of prescriptions of antiviral drugs (and diagnoses of HZ) from 2006 to 2010 in Sweden.

A number of studies have studied the cost of $\mathrm{HZ}$ and PHN covering different components and populations with a cost per patient range from 1,000 SEK $(€ 116)$ to over 20,000 SEK (€2,300). In Spain, during 2006-2007 a study published by Cebrían-Cuenca et al. [28] estimated the cost per $\mathrm{HZ}$ patient from a societal perspective to $€ 378$ (around 3,300 SEK). In this study, the most important contributing cost factors were medications, followed by primary care physician visits, accounting for $37 \%$ and $23 \%$ of the societal costs, respectively. No hospitalizations were considered in this study. Gauthier et al. [14] estimated the combined mean total cost of outpatient and inpatient health care to $£ 103(1,042$ SEK or $€ 122)$ per $\mathrm{HZ}$ case. In addition, the cost per PHN episode was estimated to $£ 397$ (3,997 SEK or €466). Most of the costs were attributed to primary care $(74 \%)$. In an Italian retrospective, population-based study [29] the costs per HZ and PHN episodes were estimated. The costs associated with inpatient and outpatient care per HZ case were $€ 2,592$ per patient (22,419 SEK) compared to $€ 123$ per patient (1,064 SEK), respectively. The corresponding figures per PHN case were $€ 2,806$ (24,270 SEK) and $€ 446$ (3,858 SEK), respectively. Scott et al. [30] showed that the medical cost were highest in those aged over 65 years and societal costs highest in those aged under 65 years. However, the overall cost of $\mathrm{HZ}$ during the first six months was estimated at $£ 524$ per patient (in 2003 UK£; $4,489$ SEK or $€ 524)$. In that study, it was also suggested from a regression analysis that increasing age, the presence of immune compromising conditions and the use of antivirals were associated with increased costs to 
Table 5 Number of sick leave days (<14 days and > =14 days) and productivity losses during 2011 for $\mathrm{HZ}$

\begin{tabular}{llll}
\hline Age groups (years) & $\begin{array}{l}\text { Number of employed } \mathrm{HZ} \\
\text { patients* }(>=50 \text { years) }\end{array}$ & $\begin{array}{l}\text { Number of HZ patients } \\
\text { on sick leave** }\end{array}$ & $\begin{array}{l}\text { Lost production cost (SEK)*** } \\
(>=50 \text { years) }\end{array}$ \\
\hline Sick leave $>=14$ days & $13822(6689)$ & 370 & $32876300(15909500)$ \\
Sick leave $<14$ days & $13822(6689)$ & 8476 & $30321300(24119200)$ \\
Total: & & & $63197600(40028700)$ \\
\hline
\end{tabular}

*Statistics Sweden; **Swedish Social Insurance Agency; ***Patients were off sick on average 51 days if sick leave $>=14$ days and 3.38 days if $<14$ days

health service while a previous history of $\mathrm{HZ}$ was associated with decreased medical costs. Finally, in a French study by Mick et al. [31] the cost per patient for the treatment of patients, older than 50 years, with $\mathrm{HZ}$ and PHN was estimated to $€ 932$ (8,061 SEK) which corresponds to what was found in our study (8,240 SEK per patient).

As different approaches to estimate the cost of $\mathrm{HZ}$ and PHN have been used in all of the above studies, direct comparisons with our results are not straightforward. A couple of the studies (Gauthier et al. [14] and Gialloreti et al. [29]) indicated that primary care was the main cost contributor which we also found in our study. CebríanCuenca et al. [28] estimated the cost per patient to 3,200 SEK (€370) per year (without hospitalizations) while Scott et al. [30] reported 4,489 SEK (€519) per six months. Both studies are in line with the 7,600 SEK (€879) per patient per year in our study.

The current study includes both direct and indirect cost which was not the case in all of the studies above. It is also a strength of the current study that register data, covering most of Sweden, were possible to collect for inpatient care, outpatient specialist care, prescribed medications and long term sick leave for $\mathrm{HZ}$ and PHN patients. A limitation of the current study, is the number of patient in inpatient care that has been estimated from ICD-10 code for HZ as the primary cause. When including patients also with $\mathrm{HZ}$ as the secondary cause, the number of hospitalizations increase by approximately $90 \%$ [8]. Another limitation is that regional data (i.e., the number of diagnostic tests from Stockholm county council and outpatient primary care from Västra Götaland county council) has been extrapolated to the whole of Sweden. However, there is no data indicating large regional differences in HZ. Therefore, it is likely that the primary care cost estimated for Sweden is reliable.

In line with the findings by Jumaan et al. [12] and Pérez-Farinós et al. [13] our study showed that both the incidence and burden of $\mathrm{HZ}$ was larger for patients above 50 years old.

There is a risk that the incidence has been overestimated since it was derived from the prescriptions of antiviral drugs in specified package sizes, which also can be prescribed to patients with other diagnoses than HZ. However, as postulated by Studahl et al. [8] it is likely that the number of diagnosed $\mathrm{HZ}$ patients exceeds the number prescriptions.
A very low mortality was identified due to $\mathrm{HZ}$ with only 11 fatalities identified. Considering the minimum yearly incidence of VZV central nervous system (CNS) disease of 1.8 per 100,000 with a significant mortality in encephalitic cases and reports of cerebral vasculitis complications due to VZV in the mistaken for common stroke, this might be an underestimate of the true VZV associated both morbidity and mortality [32, 33].

To the best of our knowledge no registry in Sweden contains data for short term sick leave i.e., shorter than 14 days. The assumption made here was 3.4 days per worker patient based on Drolet et al. [23]. Sensitivity analysis showed that the total cost increased with $6 \%$ when the number of short term sick leave days was increased with $50 \%$. As the actual number of short term sick-leave days is not available in Sweden, future studies could benefit from acquiring more precise data for this variable. Moreover, in the current study it was decided not to include the cost for patients to travel to the physician or the hospital in our analysis. This would have included the cost for public transportation or the cost for travel by car to the nearest hospital or primary care center. Since the incidence of HZ/PHN increases with age many patients are old and may need help by an accompanying person when they visit the physician. This person is often a relative who needs to take time off from work to accompany the patient. The societal cost for productivity losses for the carer has not been taken into account in this study. Although the travel and carer cost most likely would not be insignificant, the estimations would have been based on crude assumptions, e.g., distance to hospital, type of transportation and who the average carer is. Since no real data was available to support any assumptions it was decided to exclude the transportation costs and the productivity loss of the carer in this study.

It was found that a considerable part of the societal cost for the treatment of HZ and PHN (168 MSEK (19.2 M€) corresponds to $74 \%$ ) are incurred by patients 50 years and older (corresponding to $78 \%$ of the cases of $\mathrm{HZ}$ and PHN). Zostavax, a high-titer lived attenuated virus vaccine, is indicated for the prevention of $\mathrm{HZ}$ and $\mathrm{PHN}$ in adults 50 years of age and older in the EU. Its efficacy has been tested in a large randomized, double-blind, placebocontrolled trials (Shingles Prevention Study, SPS) [34]. This study reported that the vaccination reduced the 
incidence of $\mathrm{HZ}$ by $51.1 \%$ and of PHN by $66.5 \%$ in 38,546 immune competent adults aged 60 and older over a mean surveillance period of 3.1 years. It reduced the burden of illness due to $\mathrm{HZ}$ by $61.1 \%$, in that vaccinated individuals who developed $\mathrm{HZ}$ had a shorter duration, reduced disease severity and discomfort from pain compared to individuals from the placebo group who developed HZ [34]. The effect of the vaccine was confirmed by Schmader et al. [35] in the Zostavax Efficacy and Safety Trial (ZEST), where the incidence of HZ was reduced significantly (vaccine efficacy of 69.8 $\%$ ) in patients between $50-59$ years old and was well tolerated.

\section{Conclusions}

The clinical and economic burden of $\mathrm{HZ}$ and PHN is significant in Sweden and the current study estimates that $74 \%$ of the total costs are incurred by patients 50 years and older. Therefore, there is a potential for reducing the societal burden of these diseases through vaccination programs targeted at this group of patients that is likely to increase in the future. Although there are costs associated with a vaccination program, these need to be balanced against the likely reduction in disease burden and potential improvement of quality-of-life for many patients.

\footnotetext{
Abbreviations

VZV: Varicella-zoster virus; $\mathrm{HZ}$ : Herpes zoster; PHN: Post-herpetic neuralgia; ICD-10: International classification of diseases; KPP: Cost per patient database; GP: General practitioner; VGR: Västra Götaland county council; SSIA: Swedish Social Insurance Agency.
}

\section{Competing interests}

The authors declare that they have no financial or non-financial competing interest.

\section{Authors' contribution}

JN has been responsible for the design of the study, data collection, analyses and drafting of the manuscript. TC has been involved in the design of the study and drafting of the manuscript. LL has made substantial contributions in the design of the study, analysis and interpretation of data and been involved in revising the manuscript critically for important intellectual content. All authors approved the final version of the manuscript.

\section{Author details \\ ${ }^{1}$ Mapi Group, Stockholm, Klarabergsviadukten 90D, SE-111 64, Stockholm, Sweden. ${ }^{2}$ Sanofi Pasteur MSD, Solna, Sweden. ${ }^{3}$ Karolinska Institutet, Department of Medicine, Huddinge, Sweden.}

Received: 12 August 2013 Accepted: 13 May 2015

Published online: 22 May 2015

\section{References}

1. Gnann Jr JW, Whitley RJ. Clinical practice. Herpes zoster N Engl J Med. 2002;347:340-6.

2. Brisson $M$, Edmunds WJ. Epidemiology of varicella-zoster virus in England and Wales. J Med Virol. 2003;70 Suppl 1:S9-S14.

3. Insinga RP, Itzler RF, Pellissier JM, Saddier P, Nikas AA. The incidence of herpes zoster in a United States administrative database. J Gen Intern Med. 2005;20:748-53.
4. Ultsch B, Koster I, Reinhold T, Siedler A, Krause G, Icks A, Schubert I, Wichmann $\mathrm{O}$ : Epidemiology and cost of herpes zoster and postherpetic neuralgia in Germany. Eur J Health Econ. 2013;14(6):1015-26.

5. Pierik JG, Gumbs PD, Fortanier SA, Van Steenwijk PC, Postma MJ Epidemiological characteristics and societal burden of varicella zoster virus in the Netherlands. BMC Infect Dis. 2012;12:110.

6. Pinchinat $\mathrm{S}$, Cebrian-Cuenca AM, Bricout $H$, Johnson RW. Similar herpes zoster incidence across Europe: results from a systematic literature review. BMC Infect Dis. 2013;13:170.

7. Brisson M, Edmunds WJ, Law B, Gay NJ, Walld R, Brownell M, et al. Epidemiology of varicella zoster virus infection in Canada and the United Kingdom. Epidemiol Infect. 2001;127:305-14.

8. Studahl M, Petzold M, Cassel T. Disease burden of herpes zoster in Sweden-predominance in the elderly and in women - a register based study. BMC Infect Dis. 2013;13:586.

9. Watson P. Postherpetic neuralgia. Am Fam Physician. 2011;84:690-2.

10. Johnson RW, Bouhassira D, Kassianos G, Leplege A, Schmader KE, Weinke T. The impact of herpes zoster and post-herpetic neuralgia on quality-of-life. BMC Med. 2010;8:37.

11. Yih WK, Brooks DR, Lett SM, Jumaan AO, Zhang Z, Clements KM, et al. The incidence of varicella and herpes zoster in Massachusetts as measured by the Behavioral Risk Factor Surveillance System (BRFSS) during a period of increasing varicella vaccine coverage, 1998-2003. BMC Public Health. 2005;5:68.

12. Jumaan AO, Yu O, Jackson LA, Bohlke K, Galil K, Seward JF. Incidence of herpes zoster, before and after varicella-vaccination-associated decreases in the incidence of varicella, 1992-2002. J Infect Dis. 2005;191:2002-7.

13. Perez-Farinos N, Ordobas M, Garcia-Fernandez C, Garcia-Comas L, Canellas S, Rodero I, et al. Varicella and herpes zoster in Madrid, based on the Sentinel General Practitioner Network: 1997-2004. BMC Infect Dis. 2007;7:59.

14. Gauthier A, Breuer J, Carrington D, Martin M, Remy V. Epidemiology and cost of herpes zoster and post-herpetic neuralgia in the United Kingdom. Epidemiol Infect. 2009;137:38-47.

15. Swedish Association of Local Authorities and Regions. KPP-database; www.skl.se; Accessed: 1-10-2013

16. County councils in south of Sweden. Pricelist Sydöstra sjukvårdsregionen; http://skl.se/halsasjukvard/patientinflytande/utomlansvardriksavtal.943.html; Accessed: 2-1-2013

17. Norrlands county council. Pricelist Norrlands county council; http://skl.se/ halsasjukvard/patientinflytande/utomlansvardriksavtal.943.html; Accessed: 2-1-2013

18. Stockholm county council. Pricelist Stockhlom-Gotland; http:/skl.se/halsasjukvard/ patientinflytande/utomlansvardriksavtal.943.html; Accessed: 2-1-2013

19. Sydöstra Sjukvårdsregionen. Pricelist primary care home care; http://skl.se/ halsasjukvard/patientinflytande/utomlansvardriksavtal.943.html; Accessed: 2-1-2013

20. Västra Götaland county council. Pricelist Västra Götalands regionen; http://skl.se/halsasjukvard/patientinflytande/utomlansvardriksavtal.943.html; Accessed: 2-1-2013

21. Unilab. Pricelist; www.unilab.se (personal communication); Accessed: 1-10-2013

22. Läkemedelsindustriföreningens Service AB. FASS.se - Källan om kunskap om läkemedel; http://www.fass.se/LIF/home/index.jsp; Accessed: 5-14-2013

23. Drolet M, Levin MJ, Schmader KE, Johnson R, Oxman MN, Patrick D, et al. Employment related productivity loss associated with herpes zoster and postherpetic neuralgia: a 6-month prospective study. Vaccine. 2012;30:2047-50.

24. White RR, Lenhart G, Singhal PK, Insinga RP, Itzler RF, Pellissier JM, et al. Incremental 1-year medical resource utilization and costs for patients with herpes zoster from a set of US health plans. Pharmacoeconomics. 2009;27:781-92.

25. Singhal PK, Makin C, Pellissier J, Sy L, White R, Saddier P. Work and productivity loss related to herpes zoster. J Med Econ. 2011;14:639-45.

26. Statistics Sweden (SCB). Lönestrukturstatistik; www.scb.se/; Accessed: 5-8-2013

27. Ekonomifakta. Sociala avgifter; http://www.ekonomifakta.se/sv/Fakta/ Arbetsmarknad/Arbetsgivaravgift/Sociala-avgifter/; Accessed: 5-8-2013

28. Cebrian-Cuenca AM, Diez-Domingo J, San-Martin-Rodriguez M, Puig-Barbera J, Navarro-Perez J. Epidemiology and cost of herpes zoster and postherpetic neuralgia among patients treated in primary care centres in the Valencian community of Spain. BMC Infect Dis. 2011;11:302.

29. Gialloreti LE, Merito M, Pezzotti P, Naldi L, Gatti A, Beillat M, et al. Epidemiology and economic burden of herpes zoster and post-herpetic neuralgia in Italy: a retrospective, population-based study. BMC Infect Dis. 2010;10:230 
30. Scott FT, Johnson RW, Leedham-Green M, Davies E, Edmunds WJ, Breuer J. The burden of Herpes Zoster: a prospective population based study. Vaccine. 2006;24:1308-14

31. Mick G, Gallais JL, Simon F, Pinchinat S, Bloch K, Beillat M. [Burden of herpes zoster and postherpetic neuralgia: Incidence, proportion, and associated costs in the French population aged 50 or over]. Rev Epidemiol Sante Publique. 2010;58:393-401.

32. Persson A, Bergstrom T, Lindh M, Namvar L, Studahl M. Varicella-zoster virus CNS disease-viral load, clinical manifestations and sequels. J Clin Virol. 2009:46:249-53.

33. APPELBAUM E, KREPS SI, SUNSHINE A. Herpes zoster encephalitis. Am J Med. 1962;32:25-31.

34. Oxman MN, Levin MJ, Johnson GR, Schmader KE, Straus SE, Gelb LD, et al. A vaccine to prevent herpes zoster and postherpetic neuralgia in older adults. N Engl J Med. 2005;352:2271-84.

35. Schmader KE, Levin MJ, Gnann Jr JW, McNeil SA, Vesikari T, Betts RF, et al. Efficacy, safety, and tolerability of herpes zoster vaccine in persons aged 50-59 years. Clin Infect Dis. 2012;54:922-8.

\section{Submit your next manuscript to BioMed Central and take full advantage of:}

- Convenient online submission

- Thorough peer review

- No space constraints or color figure charges

- Immediate publication on acceptance

- Inclusion in PubMed, CAS, Scopus and Google Scholar

- Research which is freely available for redistribution 